\section{Influence of Different Intellectual Disability Levels on Caries and Periodontal Disease}

Antônio Augusto Iponema Costa ${ }^{1}$, Álvaro Della Bona², Micheline Sandini Trentin²

\author{
'Department of Health Sciences, \\ URI - Universidade Regional \\ Integrada do Alto Uruguai e das \\ Missões, Erechim, RS, Brazil \\ ${ }^{2}$ Post-graduate Program in Dentistry, \\ UPF - Universidade de Passo \\ Fundo, Passo Fundo, RS, Brazil \\ Correspondence: Antônio Augusto \\ Iponema Costa, Rua Gladstone \\ Osório Marsico, 23 ap. 302, \\ 99709-160 Erechim, RS, Brasil. \\ Tel:+ 55-54-9646-8785. e-mail: \\ antonioiponema@ig.com.br
}

Oral health care is fundamental to preserve the individual integrity and consequently influences the general health. This observational, cross-sectional and analytical study evaluated the oral condition of 129 intellectually disabled individuals from the Association of Parents and Friends of Exceptional Children (APAE) in three southern Brazilian cities. Dental caries (DMFT and dmft indices) and periodontal disease (PSR index) were evaluated considering the intellectual disability level. A questionnaire on socioeconomic status (income and education level) and the last visit to a dentist was answered by the subjects' parents/guardians. The data were statistically evaluated using analysis of variance (ANOVA) and Tukey test $(\alpha=0.05)$. The mean DMFT values were $2.27,3.76$ and $0.58(p<0.05)$, and the mean $\mathrm{dmft}$ values were $1.48,1.55$ and 2.75 , respectively for subjects with mild, moderate and severe disabilities. Regarding the PSR index, 43\% of the subjects presented gingivitis without retention factor (no calculus or defective margins) with no significant differences among the three disability levels. Considering the population and the limitations of this study, the subjects presenting severe disabilities showed significantly lower mean DMFT values compared to other disability levels, probably because the caretakers are responsible for the oral hygiene of such subjects.
Key Words: intellectual disability, oral health, epidemiology.

\section{Introduction}

Dentistry has experienced constant technological and scientific innovations. Paradigm shifts induce not only dentists' reflection about their own performance and qualification, but also provide satisfactory results and motivation to the patient. Following this logic, Starfield (1) reports about the importance of keeping a more comprehensive and holistic look at patient care, considering the stomatognathic system as part of the body not segregated from it.

According to the World Health Organization (WHO), one billion people around the world have some disability, which represents approximately $15 \%$ of the world population (2). The 2010 Census reports that 23.9\% Brazilians present some disabilities, making for 45.6 million Brazilians (3).

A systematic review using 27 studies compared the oral health of intellectually disabled patients to the general population, showing that the former have worse oral hygiene and higher levels of periodontal disease in prevalence and severity (4). Yet, Nqcobo et al. (5) reported that disabled children (with learning disabilities and cerebral palsy) showed lower caries prevalence and higher treatment needs than the general population, regardless the disability type.

Relatives are essential for the care of disabled people.
Relatives often are the link between the professional and the patient. Therefore, the dentist needs to know ways to establish an expanded relation to both patient and family (6).

This study evaluated the oral health condition of intellectually disabled students at the Association of Parents and Friends of Exceptional Children (APAE) from three southern Brazilian cities. Caries experience (DMFT and $\mathrm{dmft}$ indices) and periodontal disease (PSR index) were evaluated on subjects with different intellectual disability levels, testing the hypothesis that subjects diagnosed with mild disability present better oral health condition than those with other intellectual disability levels.

\section{Material and Methods}

This study was approved by the local Ethics in Research Committee (protocol number 166.392 - Plataforma Brasil). From the total population (272 subjects) of three APAEs from southern Brazilian cities (Passo Fundo, Marau and Casca - Rio Grande do Sul State, Brazil), all subjects with intellectual disability and age between 6 and 19 years old were invited to participate in this observational, cross-sectional and analytical study. The legal guardians of 147 subjects agreed on their voluntary participation by signing an informed consent form, in accordance with the 
resolution 196/96 of the Brazilian Health Council. The three APAE centers have their own medical and dental offices where all exams were performed.

All individuals admitted to APAE are initially evaluated by a multidisciplinary team consisting of neurologist, pediatrician, psychologist, nutritionist, physical therapist, occupational therapist and social workers. All information is recorded in the APAE database, including the Wechsler Intelligence Scale for Children (WISC-III) test for the diagnosis of intellectual disability level, describing as mild, moderate, severe and profound, according to the International Classification of Diseases (ICD-10). For the present study the researchers were cleared to access such records and were supported by the multidisciplinary team.

Mean DMFT and dmft values and standard deviations for each intellectual disability level and age group are in Table 1. Subjects presenting severe disabilities had a significantly lower mean DMFT index. Mean dmft indices were not significantly different among the intellectual disability levels ( $p=0.359)$.

Caries experience was evaluated using the DMFT (decayed, missed and restored permanent teeth) and $\mathrm{dmft}$ indexes (decayed, missed and restored deciduous teeth), as described in the 4th edition of the "Instructions Manual for Basic Epidemiological Survey in Oral Health" (7). Periodontal disease was evaluated using the PSR index (8), which reports the disease level by the gingival pocket depth as measured with a CPI probe (WHO). The PSR scores are in Table 2, which shows the association between these scores and the intellectual disability levels ( $L, M$ and $S$ ) and the mean age of the subjects on each PSR score.

The intraoral examination was performed within a 5-month period by a dentist (chief evaluator) assisted by two other dentists to properly manage the subjects and record the data. The chief. evaluator participated in similar studies with the same type of population. Nevertheless, all three dentists were trained according to the Examiners Calibration Manual of National Oral Health Research SB2010 and submitted to Kappa calibration test with an agreement level of $90 \%$. Intra-examiner calibration was also performed, where a subject was re-examined at each 20 subjects (5\%).

A questionnaire on socioeconomic status (income and education level) and last visit to the dentist (considering the last 12 months) was filled out by the subject's parents/guardians. Recorded data (DMFT, dmft and PSR indices) were statistically analyzed using analysis of variance (ANOVA). Statistical differences were assessed with Tukey test $(\alpha=0.05)$ using the SPSS software (Statistical Package for Social Sciences) version
15.0 (IBM Corp., Armonk, NY, USA).

\section{Results}

Among the 147 subjects that agreed to participate, 18 could not be evaluated due to dropout reasons (hospitalization or no-show on the examination days), resulting an $87.7 \%$ response rate. Among the 129 evaluated subjects, $61 \%$ were males and 39\% females, and no subject was diagnosed with profound intellectual disability.

Regardless the disability level, gingivitis with no retention factor (score 1- no calculus or defective margins) was diagnosed in $43 \%$ of the subjects, followed by score 2 (gingivitis/mild periodontitis with retention factor) with $33 \%$. Although only few subjects $(n=12)$ were diagnosed with severe disability, $42 \%$ of them presented periodontal health (score 0). Subjects with mild and moderate disabilities showed, respectively, $40 \%$ and $46 \%$ of gingivitis with no retention factor (score 1). Only one subject was diagnosed with moderate periodontitis (PSR score 3 ) and this data was not considered for statistical analysis. No significant difference was found between PSR index and the disability levels ( $p>0.05)$. Statistical differences $(p<0.05)$ were found between PSR index and subject age, showing that gingivitis (score 2) is associated with older subjects (Table 2).

Most parents/guardians (62\%) are entitled for at least one type of social benefit from the Brazilian government

Table 1. Mean values and standard deviation of DMFT, dmft and age, according to each intellectual disability level

\begin{tabular}{lcccc}
\hline $\begin{array}{l}\text { Intellectual } \\
\text { disability }\end{array}$ & $\mathrm{n}$ & DMFT $^{*}$ & Dmft & Age (years) \\
\hline Mild & 33 & $2.27 \pm 3.62 \mathrm{~b}$ & $1.48 \pm 2.63 \mathrm{~ns}$ & $12.59 \pm 3.80 \mathrm{~ns}$ \\
Moderate & 84 & $3.76 \pm 4.20 \mathrm{~b}$ & $1.55 \pm 2.65 \mathrm{~ns}$ & $13.65 \pm 3.86 \mathrm{~ns}$ \\
Severe & 12 & $0.58 \pm 1.24 \mathrm{a}$ & $2.75 \pm 4.13 \mathrm{~ns}$ & $11.60 \pm 4.27 \mathrm{~ns}$ \\
\hline
\end{tabular}

*Means with identical lowercase letters in the same columns are not statistically different $(\mathrm{p}<0.05) .{ }^{* *} \mathrm{~ns}=$ not significant

Table 2. Number (percentage) of subjects for each PSR index score distributed by intellectual disability level and age

\begin{tabular}{ccccccc}
\hline & \multicolumn{3}{c}{ Intellectual Disability Level } & & Age (years) \\
\cline { 2 - 5 } & $\begin{array}{c}\text { PSR } \\
\mathrm{n}(\%)\end{array}$ & $\begin{array}{c}\text { Moderate } \\
\mathrm{n}(\%)\end{array}$ & $\begin{array}{c}\text { Severe } \\
\mathrm{n}(\%)\end{array}$ & $\begin{array}{c}\text { Total } \\
\mathrm{n}(\%)\end{array}$ & & Mean $\pm \mathrm{SD}^{* *}$ \\
\hline 0 & $10(30)$ & $14(17)$ & $5(42)$ & $29(23)$ & & $12.1 \pm 4.0 \mathrm{a}$ \\
1 & $13(40)$ & $39(46)$ & $4(33)$ & $56(43)$ & & $12.3 \pm 3.9 \mathrm{a}$ \\
2 & $10(30)$ & $30(36)$ & $3(25)$ & $43(33)$ & & $14.5 \pm 3.4 \mathrm{~b}$ \\
3 & 0 & $1(1)$ & 0 & $1(1)$ & & 18.0 \\
Total & 33 & 84 & 12 & 129 & & $14.2 \pm 3.8$ \\
\hline
\end{tabular}

*PSR scores: 0 = periodontal health; $1=$ Gingivitis with no retention factor; 2 = Gingivitis / mild periodontitis, with retention factor; 3 = Moderate periodontitis. ***Mean values with identical lowercase letters in the same column are not statistically different $(\mathrm{p}<0.05)$. 
and half of the subjects' families received 2-3 monthly wages (Table 3). All higher educated mothers took their children (21) to the dentist within the previous year, while only $58 \%$ of the lower educated (up to 5 th grade) mothers did the same (Table 4).

\section{Discussion}

This cross-sectional study evaluated the oral health conditions considering the intellectual disability level of 129 subjects, mostly from socially vulnerable and low education background families, therefore composing a homogeneous sample population. The hypothesis that subjects diagnosed with mild intellectual disability present better oral health condition was rejected. The present study showed that subjects with severe intellectual disabilities have the lowest mean DMFT value, suggesting they have better oral health condition than the subjects diagnosed with other intellectual disability levels. The term "suggesting" is used because of the reduced number of subjects diagnosed with severe intellectual disability. Yet, there was no significant difference between the $\mathrm{dmft}$ and PSR indices in the three levels of intellectual disability (Tables 1 and 2).

The mean DMFT values of subjects with mild, moderate and severe disabilities were, respectively, 2.27, 3.76 and 0.58 (Table 1). Subjects with severe disability have intellectual and/or motor impairment to perform their own oral hygiene, therefore, their relatives/guardians often serve as oral hygiene agent to them, which may explain such data. This observation disagrees with previous reports $(9,10)$ that

Table 3. Number (percentage) of subject family (parents/guardians) according to their total monthly income (private earnings + Government social benefit)

\begin{tabular}{lccccc}
\hline \multirow{2}{*}{$\begin{array}{l}\text { Government } \\
\text { social benefit }\end{array}$} & \multicolumn{2}{c}{ Total monthly income (in monthly wage*) } & \multirow{2}{*}{ Total } \\
\cline { 2 - 5 } & $1 \mathrm{MW}$ & $2-3 \mathrm{MW}$ & $3-5 \mathrm{MW}$ & $>5 \mathrm{MW}$ & \\
\cline { 2 - 5 } & $\mathrm{n}(\%)$ & $\mathrm{n}(\%)$ & $\mathrm{n}(\%)$ & $\mathrm{n}(\%)$ & $\mathrm{n}(\%)$ \\
\hline No & $16(36)$ & $22(34)$ & $6(55)$ & $5(56)$ & $49(38)$ \\
Yes & $29(64)$ & $42(66)$ & $5(45)$ & $4(44)$ & $80(62)$ \\
Total & $45(35)$ & $64(50)$ & $11(8)$ & $9(7)$ & $129(100)$ \\
\hline
\end{tabular}

*1 monthly wage $=$ US $\$ 330$ (May, 2013).

Table 4. Number (percentage) of subjects seen by the dentist during the last 12 months related to their mothers' education level

\begin{tabular}{lccccc}
\hline & \multicolumn{5}{c}{ Mother's education level } \\
\cline { 2 - 5 } $\begin{array}{l}\text { Dentist } \\
\text { visit }\end{array}$ & Up to $4^{\text {th }}$ grade & $5^{\text {th }}$ to $8^{\text {th }}$ grade & $9^{\text {th }}$ to $12^{\text {th }}$ grade & $\begin{array}{c}\text { Higher } \\
\text { education }\end{array}$ & $\begin{array}{c}\text { Total } \\
\text { n (\%) }\end{array}$ \\
\cline { 2 - 5 } & $\mathrm{n}(\%)$ & $\mathrm{n}(\%)$ & $\mathrm{n}(\%)$ & $\mathrm{n}(\%)$ & \\
\hline No & $22(42)$ & $9(27)$ & $11(48)$ & 0 & $42(33)$ \\
Yes & $30(58)$ & $24(73)$ & $12(52)$ & $21(100)$ & $87(67)$ \\
Total & $52(40)$ & $33(26)$ & $23(18)$ & $21(16)$ & $129(100)$ \\
\hline
\end{tabular}

suggested that the need for dental treatment increases with higher disability level and age.

According to the epidemiological survey (Project SB Brazil 2010) that considered the whole Brazilian population, the $\mathrm{dmft}$ index at 5 years of age was 2.3, while the DMFT index at ages of 12 and 15-19 were, respectively, 2.1 and 4, 2. In the same Brazilian State (Rio Grande do Sul - RS) of the present study, the $\mathrm{dmft}$ index at 5 years of age was 1.71, the DMFT index at 12 years of age was 1.49 and at 15-19 years of age was 2.98 (11). The DMFT index (1.49) for the RS State is considered "low" (1.1 - 2.6) according to WHO (7). Yet, almost half (49\%) of the study subjects showed a "very low" (up to 1.1) DMFT index, which was represented by $67 \%, 38 \%$ and $84 \%$, respectively, for mild, moderate and severe disability subjects.

The mean $\mathrm{dmft}$ values of subjects with mild, moderate and severe disabilities were $1.48,1.55$ and 2.75 , respectively. Although there was no significant difference, there is a trend for subjects with severe disabilities to present greater $\mathrm{dmft}$ values. This may be explained because of (1) the high mean age (close to 12 years of age) for the $\mathrm{dmft}$ index and (2) the parents' guilty feelings of generating a disabled child, being thus more permissive to an early cariogenic diet. Usually, after some time this feeling is surpassed with the aid of professionals to take care of children's oral health. These considerations are based on studies with Taiwanese children from 6 to 12 years of age with different levels of intellectual disability, presenting high caries prevalence corresponding to poor oral hygiene and sweets intake just after meals (12). The oral hygiene of intellectually disabled children is remarkably difficult and they need help from their relatives (13).

In the present study, the most used drugs were anticonvulsants, anxiolytics and muscle relaxants. Depending on the drug, important gingival alterations may occur if dental plaque is not well controlled. Anticonvulsants (phenytoin) stand out because of their great potential for gingival hyperplasia. There have been reports that people with intellectual disabilities have higher risk of caries and periodontal disease due to the use of psychoactive drugs that induce xerostomy (14). The drugs mostly related to xerostomy are antihypertensives, antidepressants and anticonvulsants $(15,16)$.

The present study showed that most $(43 \%)$ of the subjects had gingivitis with no retention factor (no calculus or defective margins). Therefore, the relatives were instructed to take the subjects more often to the dentist in order to control plaque 
accumulation and get oral hygiene instructions. Fortythree subjects (33\%) showed gingivitis/mild periodontitis with retention factor (score 2) in the PSR exam and were submitted to scaling and polishing, removal of restoration excesses and oral hygiene instructions, according to the protocol proposed by Santos Júnior et al. (17).

A great percentage (42\%) of severely disabled subjects presented no sign of periodontal disease. Like the DMFT index, this good oral health may be related to relative's commitment to serve as oral hygiene agents to their children, while others with mild to moderate disabilities have more freedom to carry out their own hygiene without supervision, which may result in poor oral health conditions.

Periodontal (scraping, smoothing and supragingival polishing) and restorative treatments were the most relevant needs. Salles et al. (18) reported that tooth extractions and restorative procedures were the most common needs for people with intellectual disabilities. Therefore, health professionals should carry out educational activities to promote oral health, disease prevention, rehabilitation, healthy diet and oral hygiene instructions for subjects with disabilities and their parents/guardians, who are often responsible for their oral hygiene. Comprehensive care of subjects from APAE must provide them a better quality of life.

Considering the evaluated population and the limitations of this study, the results showed that subjects with severe intellectual disability have lower DMFT index and better oral health conditions than the subjects with other disability levels. Mean $\mathrm{dmft}$ and PSR values were not significantly different among the three disability levels.

\section{Resumo}

Os cuidados com a saúde bucal são de fundamental importância para a preservação da integridade do indivíduo e, consequentemente, refletem na saúde geral. Este estudo transversal, observacional e analitico avaliou a situação bucal de 129 alunos com deficiência intelectual matriculados na Associação de Pais e Amigos dos Excepcionais (APAE) de três municípios do sul do Brasil. Cárie dentária (índices CPO-D e ceo-d) e doença periodontal (indice PSR) foram avaliados considerando o nível de deficiência intelectual. Um questionário das condições socioeconômicas (renda e escolaridade) e última visita ao dentista foi respondida pelos pais/responsáveis. Os dados foram avaliados estatisticamente utilizando análise de variância (ANOVA) e teste Tukey $(\alpha=0,05)$. As médias no índice CPO-D foram de $2,27,3,76$ e $0,58(p<0,05)$ e no índice ceo-d foram de $1,48,1,55$ e 2,75 para os alunos com deficiência leve, moderada e severa, respectivamente. Com relação ao índice PSR, 43\% dos alunos apresentou gengivite sem fator de retenção (sem cálculo ou defeitos marginais), não tendo diferença estatística entre os três niveis de deficiência. Considerando a população e as limitações do estudo, observou-se que alunos com deficiência severa apresentaram índice CPO-D significativamente menor comparado com outros níveis de deficiência, provavelmente devido à higiene oral ser realizada pelos cuidadores/responsáveis. technology. Brasilia: UNESCO Brazil, Ministry of Health, 2002.

2. World Health Organization (WHO). World report on disability Translation: Lexicus Language Services. São Paulo: EDPCD, 2012.

3. Brazilian Institute of Geography and Statistics (IBGE). Aggregated Database. Population Census 2010: general characteristics of the population, religion and disability. [internet]. 2012 [cited 29 May 2015] Available from: <http://www.sidra.ibge.gov.br/cd/cd2010CGP. asp? $0=13 C \mathrm{ti}=\mathrm{P}>$.

4. Anders PL, Davis EL. Oral health of patients with intellectual disabilities: a systematic review. Spec Care Dentist 2010;30:110-117.

5. Nqcobo CB, Yengopal V, Rudikph MJ, Thekiso M, Joosab Z. Dental caries prevalence in children attending special needs schools in Johannesburg, Gauteng Province, South Africa. SADJ 2012;67:308-313.

6. Costa AAI, Della Bona A. Dental care for deaf-blind patients: facing challenges. RFO 2013;18:107-111.

7. World Health Organization. Oral health surveys: basic methods. 4 ed. Geneva: ORH/EPID; 1997.

8. American Dental Association \& American Academy of Periodontology. Periodontal Screening and Recording. Training Program. Procter \& Gamble; 1992

9. Huang ST, Hurng S, Liu HY, Chen CC, Hu WC, Tai Y, Hsuao SY. The oral health status and treatment needs of institutionalized children with cerebral palsy in Taiwan. J Dent Sci 2010;5:75-89.

10. Gondim LAM, Andrade MC, Maciel SSSV, Ferreira MAF. Epidemiological profile of dental conditions and treatment needs of the disabled in the city of Caruaru, PE, Brazil. RGO 2008;56:393-397.

11. Brazil. Ministry of Health. National Oral Health Research. Notice to the Press. Brasilia, 2010.

12. Liu HY, Huang ST, Hsuao SY, Chen CC, Hu WC, Yen YY. Dental caries associated with dietary and tooth brushing habits of 6- to 12-year-old mentally retarded children in Taiwan. J Dent Sci 2009;4:61-74.

13. Altun C, Guven G, Akgun OM, Akkurt MD, Basak F, Akbulut E. Oral health status of disabled individuals attending special schools. Eur J Dent 2010;4:361-366.

14. Carvalho EMC, Araújo RPC. Oral health in people with mental and behavioral disorders. Pesq Bras Odontoped Clin Integr 2004;4:65-75.

15. Perotto JH, Andrades KMR, Paza AO, Ávila LFC. Xerostomy prevalence related to medication in patients treated at the Dental School of UNIVILLE. RSBO 2007;4:16-19.

16. Tekavec MM, Tekavec CD. PSR provides new patient-management tool. Dent Econ 1993;83:69-74.

17. Santos Júnior GC, Barnabe $W$, Rubo JH, Greghi SLA. Periodontal screening and recording (PSR) in patients for prosthetic treatment. Rev Fac Odontol Bauru 2002;10:113-117.

18. Salles PS, Tannure PN, Oliveira CA, Souza IP, Portela MB, Castro GF. Dental needs and management of children with special healthcare needs according to type of disability. J Dent Child 2012;79:165-169.

Received July 24, 2015 Accepted December 21, 2015

\section{References}

1. Starfield B. Primary Care: Balancing needs for health, services and 